\title{
Minimally Invasive, Stereotactic, Wireless, Percutaneous Pedicle Screw Placement in the Lumbar Spine: Accuracy Rates With 182 Consecutive Screws
}

\author{
SAEED S. SADRAMELI, MD, MS, RYAN JAFRANI, MD, BLAKE N. STAUB, MD, MAJDI RADAIDEH, MD, \\ PAUL J. HOLMAN, MD \\ Houston Methodist Neurosurgical Spine Center, Houston Methodist Neurological Institute, Houston, Texas
}

\begin{abstract}
Background: Standard fluoroscopic navigation and stereotactic computed tomography-guided lumbar pedicle screw instrumentation traditionally relied on the placement of Kirshner wires (K-wires) to ensure accurate screw placement. The use of $\mathrm{K}$-wires, however, is associated with a risk of morbidity due to potential ventral displacement into the retroperitoneum. We report our experience using a computer image-guided, wireless method for pedicle screw placement. We hypothesize that minimally invasive, wireless pedicle screw placement is as accurate and safe as the traditional technique using $\mathrm{K}$-wires while decreasing operative time and avoiding potential complications associated with K-wires.

Methods: We conducted a retrospective review of 42 consecutive patients who underwent a stereotactic-guided, wireless lumbar pedicle screw placement. All screws were placed to provide fixation to a variety of interbody fusion constructs including anterior lumbar interbody fusion, lateral interbody fusion, and transforaminal lumbar interbody fusion. The procedures were performed using the O-arm intraoperative imaging system with StealthStation navigation (Medtronic, Memphis, TN) and Medtronic navigated instrumentation. After placing a percutaneous navigation frame into the posterior superior iliac spine or onto an adjacent spinous process, an intraoperative O-arm image was obtained to allow subsequent StealthStation navigation. Para-median incisions were selected to allow precise percutaneous access to the target pedicles. The pedicles were cannulated using either a stereotactic drill or a novel awl-tipped tap along with a low-speed/high-torque power driver. The initial trajectory into the pedicle was recorded on the Medtronic StealthStation prior to removal of the drill or awl-tap, creating a "virtual" K-wire rather than inserting an actual Kwire to allow subsequent tapping and screw insertion. Accurate screw placement is achieved by following the virtual path as an exact computer-aided design model of the screw traversing the pedicle is projected onto the display and by using audible and tactile feedback. A second O-arm scan was obtained to confirm accuracy of screw placement.

Results: A total of 20 women and 22 men (average age $=56$ years) underwent a total of 182 pedicle screw placements using the stereotactic, wireless technique. The total breach rate was $9.9 \%$, with a clinically significant breach rate of $0 \%$ (defined as $>2 \mathrm{~mm}$ medial breach or $>4 \mathrm{~mm}$ lateral breach) and a clinical complication rate of $0 \%$.

Conclusions: Wireless, percutaneous placement of lumbar pedicle screws using computed tomography-guided stereotactic navigation is a safe, reproducible technique with very high accuracy rates.
\end{abstract}

Minimally Invasive Surgery

Keywords: MIS spinal fusion, neuro-navigation, K-wireless, percutaneous pedicle placement accuracy

\section{INTRODUCTION}

Posterior spinal instrumentation via pedicle screw-rod fixation is the standard of care for various spine diseases of degenerative, traumatic, infectious, and neoplastic origin. ${ }^{1-12}$ Minimally invasive surgical (MIS) placement of pedicle screws has become increasingly common, offering benefits superior to traditional open techniques including reduction of postoperative pain, shorter hospital stay, minimal disruption of the posterior stabilizing structures, and decreased risk of infection and operative time. ${ }^{13-17}$ Originally described in 1977 by Magerl et al, ${ }^{18}$ percutaneous placement of pedicle screws is now commonly used with MIS interbody fusion techniques. Some of these include anterior lumbar interbody fusion (ALIF), lateral interbody fusion (LLIF, XLIF, OLIF), and transforaminal lumbar interbody fusion (TLIF). ${ }^{18}$

Minimally invasive spinal instrumentation traditionally relied on the use of Kirshner wires (K-wires) to ensure accurate screw placement. However, K- 
wires are associated with the added morbidity of potential violation of the retroperitoneum and malfunctions such as bending, breaking, and decannulating. ${ }^{19,20}$ Recently, a "K-wireless" percutaneous pedicle screw placement technique was published by Spitz et $\mathrm{al}^{21}$ that uses intraoperative fluoroscopy for localization. This method is technically feasible and provides a safe alternative to the use of K-wires. $^{21}$

At our institution, we have modified the Spitz technique by using intraoperative image-guided stereotactic navigation rather than fluoroscopy for pedicle screw placement to provide increased speed and precision, all while reducing the radiation exposure of operating personnel. Information on the $\mathrm{K}$-wireless technique is limited, and, to our knowledge, using intraoperative image-guided stereotactic navigation has not been reported. The purpose of this study is to review our experience with $\mathrm{K}$-wireless percutaneous pedicle screw placement using intraoperative image-guided stereotactic navigation.

\section{MATERIALS AND METHODS}

Retrospectively collected data from our institution were reviewed, consisting of the first 42 consecutive patients who underwent lumbosacral instrumentation using the stereotactic, K-wireless technique between 2012 and 2014. Chart review included patient demographics, indication for surgery, type of operation, number of levels fused, screw placement accuracy, and complications. Pedicle screw placement accuracy was determined using either intraoperative postplacement O-arm scans or outpatient follow-up computed tomography (CT) studies. In all cases, either single or multilevel interbody fusion was performed using ALIF, OLIF, XLIF, LLIF, or TLIF interbody fusion technique (Table 1).

\section{Surgical Technique}

All cases were performed using the O-arm conebeam CT intraoperative imaging system integrated with the StealthStation navigation system (Medtronic, Memphis, Tennessee) and Medtronic instrumentation. All pedicle screws were inserted following interbody graft placement during the same operation. A percutaneous, fixed navigation frame was placed in the posterior superior iliac spine. Alternatively, the navigation frame can also
Table 1. Description of patients' baseline characteristics, level fused, and interbody placement approach.

\begin{tabular}{lc}
\hline Variable & Value \\
\hline Patients & 42 \\
Mean age in y (range) & $56(20-77)$ \\
Men, n (\%) & $22(52)$ \\
Women, n (\%) & $20(48)$ \\
Number of screws at vertebral level (\%) & \\
L1 & $0(0)$ \\
L2 & $4(2.2)$ \\
L3 & $16(8.8)$ \\
L4 & $59(32.4)$ \\
L5 & $59(32.4)$ \\
S1 & $44(24.2)$ \\
Total & $182(100)$ \\
Number of procedures & 24 \\
ALIF & 11 \\
LLIF & 4 \\
TLIF & 3 \\
OLIF & 3 \\
\hline
\end{tabular}

Abbreviations: ALIF, anterior lumbar interbody fusion; LLIF, lateral interbody fusion; OLIF, oblique lateral interbody fusion; TLIF, transforaminal lumbar interbody fusion.

be attached to a spinous process, above or below the levels of instrumentation. Next, the O-arm intraoperative imaging system was brought into the field. A $360^{\circ}$ spin was performed and the images were transferred to the Medtronic StealthStation for stereotactic screw guidance. Symmetric para-median incisions were made on the basis of number of levels to be instrumented and positioned to allow a convergent trajectory through the pedicle into the vertebral body (Figure 2A). The pilot holes are drilled with a long matchstick burr within a navigated universal drill guide. The trajectory plan, or "virtual K-wire," was saved on the Medtronic StealthStation prior to removal of the drill bit. Rather than inserting a K-wire at this point, the drill and drill guide were removed. Using the saved plan as a visual cue along with tactile feel, the pilot holes were easily re-entered and tapped with an imageguided tap. Alternatively, our preferred technique now uses a novel "awl-tipped tap" (Figures 1 and 2B), which allows for penetration of the cortical bone at the screw entry site, initial passage into the pedicle, and tapping through the pedicle into the vertebral body. This tap changes from a small to larger diameter along its shaft; we prefer 4.5 to 5.5 $\mathrm{mm}$ for lumbar pedicle screws. This instrument was inserted using a low-speed/high-torque Powerase driver (Medtronic) that (Figure 2D and E) optimizes navigation accuracy by limiting the displacement of the spine associated with advancement through the pedicle. The screws were then inserted using a navigated screwdriver, aided by the saved trajectory plan (Figure 2C). At this point, percutaneous rods 

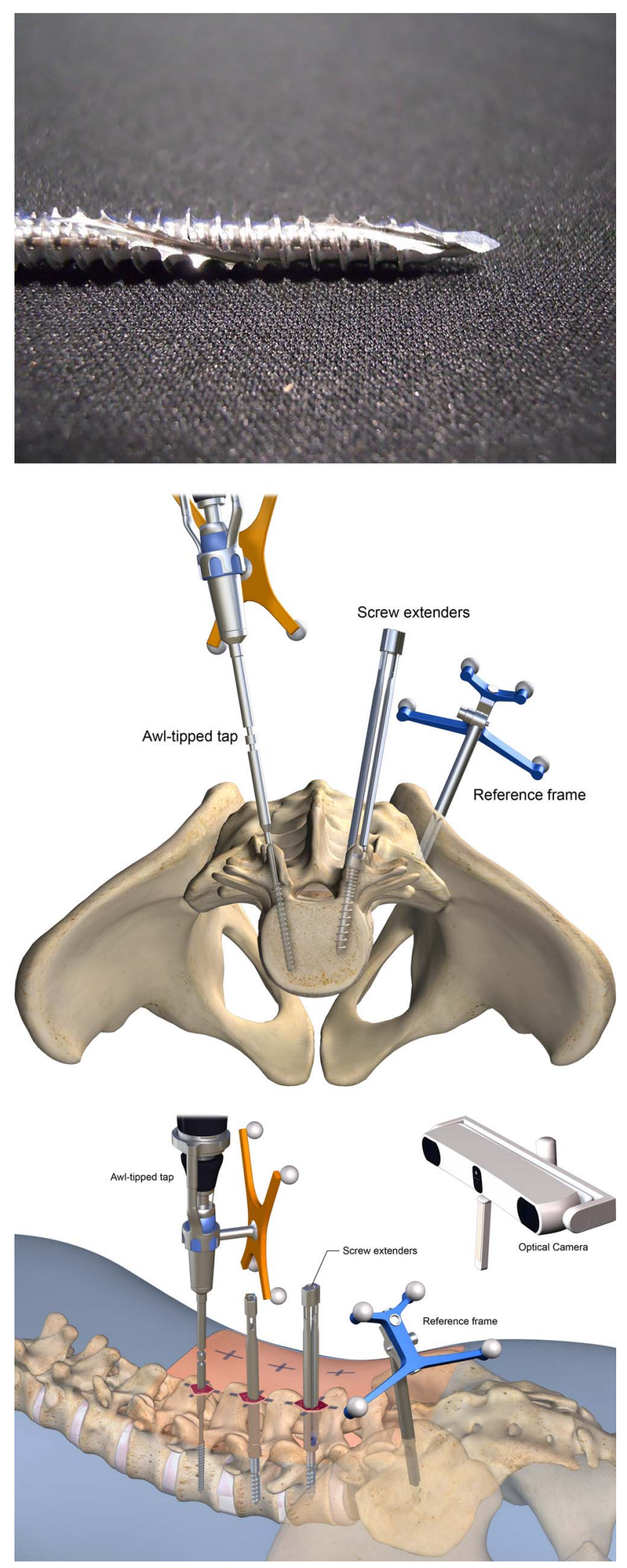

Figure 1. Schematic and equipment for "K-wireless" navigated minimally invasive pedicle screw placement: "awl-tipped tap" that allows for penetration of the cortical bone at the screw entry site, initial passage into the pedicle, and tapping through the pedicle into the vertebral body. This tap changes from a were placed and any indicated compression, distraction, and/or reduction maneuvers were performed. A second O-arm CT scan was performed to confirm accurate screw placement prior to tightening of locking caps. Last, the wound was irrigated copiously and closed in layers in standard fashion.

\section{Accuracy Assessment}

The Gertzbein classification was used by a senior neuro-radiologist, blinded to patient data and outcomes, to analyze the degree of pedicle screw accuracy (Table 2). Postinstrumentation axial views of the lumbosacral spine along with sagittal and coronal reconstruction images were analyzed using OsiriX Imaging Software (Geneva, Switzerland). Pedicles were inspected medially, laterally, superiorly, and inferiorly for presence of cortical breach. Screw placement accuracy and pedicular breaches were assessed and subdivided into Grades 0 through 3 , depending on the extent of breach: 0 , completely within the confines of the pedicle; 1, pedicle wall breach of less than $2 \mathrm{~mm}$; 2, pedicle wall breach between 2 and $4 \mathrm{~mm}$; and 3, pedicle wall breach greater than $4 \mathrm{~mm}$. There were no specific inclusion or exclusion criteria; all patients deemed appropriate for placement of posterior lumbosacral percutaneous pedicle screws were included in our study.

\section{RESULTS}

A total of 182 pedicle screws were placed in 42 consecutive patients (22 men, 20 women) using the stereotactic, wireless technique. Screw accuracy was assessed using intraoperative postinstrumentation $\mathrm{O}$-arm scans in 34 patients, whereas postoperative CT scans performed at follow-up visits were used in 8 patients. A total of 44 screws were placed in the sacral spine (S1) and 138 in the lumbar spine (Table 3). Patient age ranged from 20 to 77 years, with a mean age of 56 years. Radiologic assessment of pedicle screws revealed 13 screws with a minimal cortical breach of less than $2 \mathrm{~mm}$ (Grade 1), 5 screws with 2 to $4 \mathrm{~mm}$ (Grade 2), and no screws with greater than $4 \mathrm{~mm}$ (Grade 3), whereas 164 screws

small to larger diameter along its shaft, and we prefer the 4.5- to 5.5-mm option for lumbar pedicle screws. This instrument is inserted with a low-speed/hightorque Powerase driver. All cases were performed using the O-arm cone beam computed tomography intraoperative imaging system integrated with the StealthStation navigation system and Medtronic instrumentation. Registration is automatic with this system. 

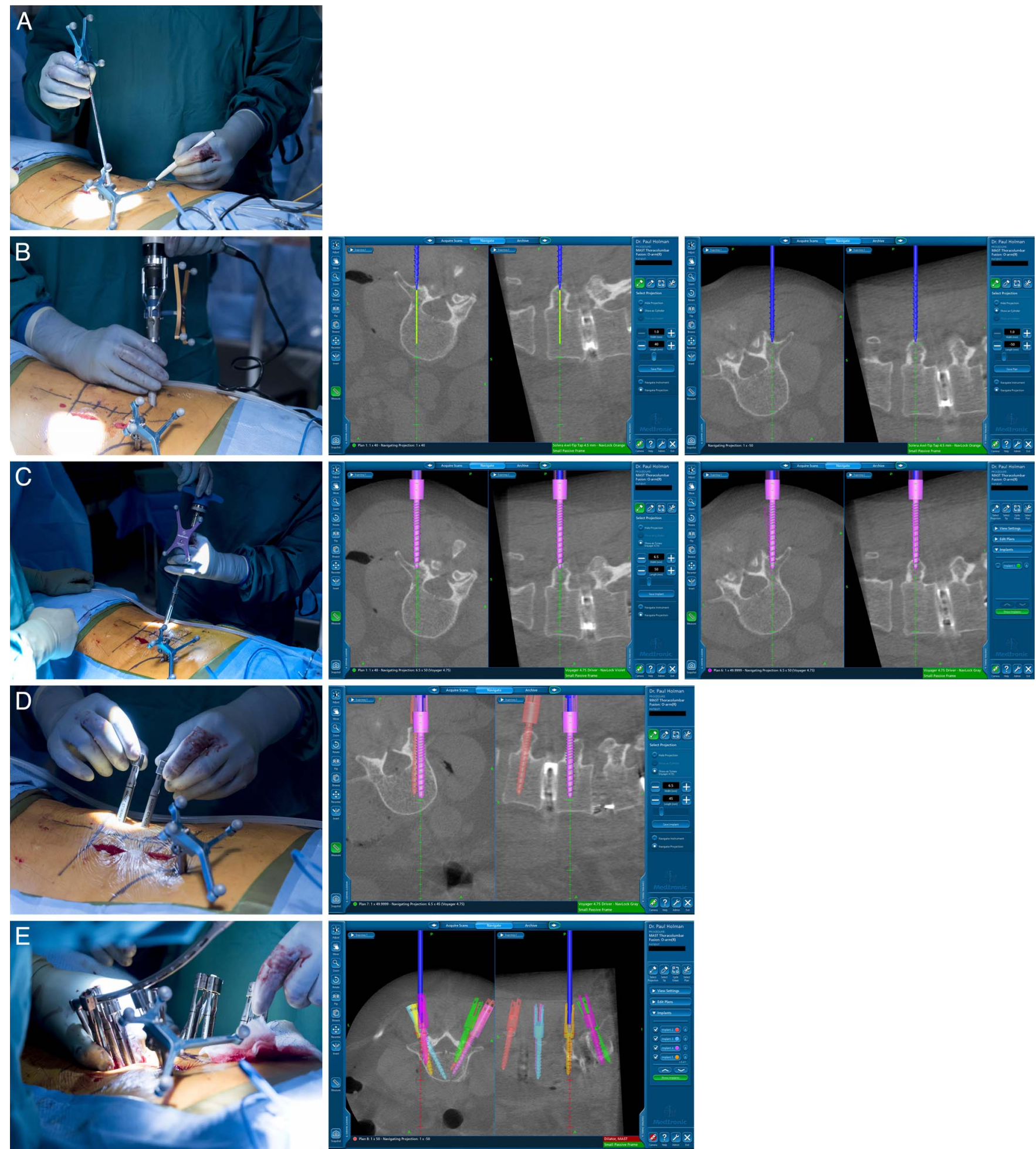

Figure 2. Intraoperative pictures and with corresponding neuronavigation for "K-wireless" navigated pedicle screw placement. (A) Navigation is used to mark the incision providing the desired convergent trajectory through the pedicle, minimizing the size of the incision needed. (B) The "awl-tipped tap" is used to make a trajectory plan or "virtual K-wire," followed by tapping of the pedicle, aided by the saved trajectory plan, without the need for pilot holes. (C) Screw placement is aided by the saved trajectory plan. (D) This is repeated for each subsequent pedicle screw. (E) Percutaneous rod placement. 
Table 2. Gertzbein classification.

\begin{tabular}{ll}
\hline Grade & Breach Distance \\
\hline 0 & $0 \mathrm{~mm}$ (no breach) \\
1 & $<2 \mathrm{~mm}$ \\
2 & $2-4 \mathrm{~mm}$ \\
3 & $>4 \mathrm{~mm}$ \\
\hline
\end{tabular}

were placed completely within the pedicle (Grade 0 ). All breaches involved the lateral wall of the pedicle; none resulted in clinically significant patient morbidity immediately postoperatively or at 9-month follow-up. The total breach rate was $9.9 \%$, with a clinically significant breach rate of $0 \%$ (defined as $>2-\mathrm{mm}$ medial or inferior breach, or $>4-\mathrm{mm}$ lateral or superior breach). If Grade 1 breaches were excluded, the breach rate was $2.7 \%$. In cases where the instrumentation scatter associated with intraoperative $\mathrm{O}$-arm scans made the presence of a breach questionable, the case was downgraded to simulate the worst-case scenario for data analysis.

\section{DISCUSSION}

Pedicle screw-rod fixation was first introduced in the 1950 s by $\mathrm{H}$. Boucher, ${ }^{22}$ was popularized in the 1980 s, and is now the standard in adult spinal fusion due to superior biomechanical pullout strength and powerful segmental corrective forces, allowing for enhanced deformity correction. ${ }^{23}$ The traditional open pedicle screw insertion technique requires extensive soft tissue and muscle dissection to expose necessary bony structures and to accommodate the angles required for screw placement. In the last 15 years, minimally invasive or percutaneous pedicle screw placement has allowed surgeons to segmentally fixate the spine through smaller incisions with minimal soft tissue dissection $^{24}$; multiple studies have demonstrated the safety, efficacy, and accuracy of this technique for internal spinal fixation. ${ }^{1-4,7,8,10,16,25-31}$ Percutaneous techniques demonstrate significant benefits to patients via decrease in overall operative times, pain, blood loss, risk of infection, and length of hospital stay. ${ }^{13-16,32}$

Whereas fluoroscopic guidance is used for accurate placement of percutaneous screws, the 2dimensional (2D) nature of this imaging modality is a major drawback. Pedicle screw placement, using intraoperative navigation, provides accurate location of the screw relative to the canal and ventral vascular structures, in addition to medial and lateral pedicle borders. Image-guided navigation is increasingly used in the setting of spinal operations to visualize unexposed anatomy. ${ }^{33,34}$ Image-guided spinal navigation techniques are an alternative to the traditional use of fluoroscopy to improve accuracy, decrease operative time, and minimize radiation exposure. ${ }^{35-38}$ Multiple studies have shown 3-dimensional CT-based navigation to be more accurate than traditional 2D fluoroscopic guidance of pedicle screw placement. Steinmann et $\mathrm{al}^{39}$ initially looked at the benefit of axial imaging in pedicle screw placement in cadaver specimens combining fluoroscopic 2D images with CT axial images. They demonstrated an error rate of $5.5 \%$ compared with $21 \%$ to $31 \%$ in numerous contemporary studies. ${ }^{39}$ Given that the use of CT navigation has increased over recent years, a large body of clinical data highlights the advantages of CT-navigated pedicle screw placement compared with traditional fluoroscopy. ${ }^{40-44}$ Waschke et $\mathrm{al}^{44}$ compared 2422 screws placed with CT navigation with 2002 placed with fluoroscopy in the thoracolumbar spine. In the lumbar spine, they showed a statistically significant increase in accuracy from $93.9 \%$ to $96.4 \%$ in the CT-navigation group $(P=$ $.001)$. Their results were even more dramatic in the thoracic spine, where accuracy improved from $79.0 \%$ to $95.5 \%$ in the CT-navigated group $(P<$ .001). ${ }^{44}$ Luther et $\mathrm{al}^{40}$ likewise demonstrated a statistically significant increase in accuracy from $82 \%$ to $88 \%$ with CT navigation in a series of 1434 pedicle screws in 260 patients $(P<.001)$. A recent meta-analysis of 68 pertinent studies, including 3442

Table 3. Number, degree, and direction of pedicle screw breach at each level.

\begin{tabular}{|c|c|c|c|c|c|}
\hline Vertebral Level & Screws per Vertebral Level & No. of Breaches & Direction of Breach (n) & Grade of Breach (n) & Breach Rate (\%) \\
\hline L1 & 0 & 0 & $\mathrm{~N} / \mathrm{A}$ & $\mathrm{N} / \mathrm{A}$ & 0 \\
\hline L2 & 4 & 2 & Lateral (2) & $1(1), 2(1)$ & 50 \\
\hline L3 & 16 & 3 & Lateral (3) & $1(1), 2(2)$ & 19 \\
\hline L4 & 59 & 9 & Lateral (9) & $1(7), 2(2)$ & 15.3 \\
\hline L5 & 59 & 4 & Lateral (2), inferior (2) & $1(4)$ & 6.8 \\
\hline $\mathrm{S} 1$ & 44 & 0 & $\mathrm{~N} / \mathrm{A}$ & $\mathrm{N} / \mathrm{A}$ & 0 \\
\hline Total & 182 & 18 & & & 9.9 \\
\hline
\end{tabular}

Abbreviation: N/A, nonapplicable. 
patients, 60 cadavers, and 43305 pedicle screws, came to similar conclusions. Pedicle screw accuracy (defined as $<2-\mathrm{mm}$ breach) improved from $91.4 \%$ with fluoroscopy to $97.3 \%$ with CT navigation $(P<$ $.001)^{45}$

Percutaneous pedicle screw placement techniques typically rely on the fluoroscopic placement of Jamshidi (Becton, Dickinson and Company, Franklin Lakes, New Jersey) needles through the pedicle with subsequent placement of bendable K-wires to maintain the proper path for subsequent placement of taps and screws. K-wires, however, create some unique technical challenges in screw placement as well as operative risks to the patients. Although injury via $\mathrm{K}$-wire misplacement, fracture, or migration is uncommon, the potential for catastrophic vascular or visceral injury exists and is likely underreported. Complications reported in the literature include cerebrospinal fluid leak, retroperitoneal hematoma, ileus, paraplegia, and one instance of fatal cardiac tamponade. ${ }^{20,46-48}$ Fessler et $\mathrm{al}^{47}$ reported K-wire fracture in 6 of 513 patients retrospectively reviewed. Of those 6 patients, one had a cerebrospinal fluid leak and another had postoperative ileus, requiring a reoperation for hardware removal. Heini et al ${ }^{19}$ reported 7 anterior vertebral body breaches in 525 placed pedicle screws, resulting in retroperitoneal hematoma and ileus in 2 patients. In addition to risk to patients, inadvertent bending and displacement of $\mathrm{K}$-wires is fairly common and can lead to prolonged surgical time and surgeon frustration. Although data are very limited, new $\mathrm{K}$-wireless techniques are emerging that maintain the accuracy provided by $\mathrm{K}$-wires while removing their associated limitations and risks. Spitz et $\mathrm{al}^{21}$ recently described confident results using this $\mathrm{K}$-wireless technique with a total breach rate of $3.6 \%$, a clinically significant breach rate of $1.1 \%$ (Gertzbein grade 2 or 3 ), and a clinical complication rate of $3.6 \%$ in a series of 100 pedicle screws placed in 28 patients. The results of the present study are comparable, with a total breach rate of $9.9 \%$, a clinically significant breach rate of $2.7 \%$ (or $0 \%$ if lateral breaches are considered clinically significant only when $>4 \mathrm{~mm}$ ), and a clinical complication rate of $0 \%$ in a series of 182 pedicle screws placed in 42 patients.

Although these early results regarding the accuracy of $\mathrm{K}$-wireless technique are very promising, direct comparison is difficult considering the limited published data on the K-wireless technique and that the reported breach rates for open and percutaneous $\mathrm{K}$-wire dependent techniques vary greatly within the literature. Contributing to this challenge is the lack of a standard for screw misplacement and postplacement evaluation. ${ }^{44}$ Reported breach rates for the traditional open technique are as high as $39 \%$. With use of 2D fluoroscopy, breach rates via the open technique have been reported between $5 \%$ and $23 \%$. Breach rates for percutaneous K-wire-dependent screw placement have been reported between $6.2 \%$ and $23 \%$. The clinical complication rate, or neurological injury, from misplaced screws using the percutaneous K-wire method is between $2 \%$ and $12.5 \%$, comparable with the results from the $2 \mathrm{~K}$ wireless datasets available $(3.6 \%$ previously published and $0 \%$ in the present study). ${ }^{49-54}$

In the present study, there were 18 total breaches out of 188 pedicle screws placed, representing a breach rate of $9.9 \%$, or $90.1 \%$ accuracy. It is generally accepted that lateral and superior pedicle breaches are safer than medial and inferior breaches due to the greater distance between neural elements and the lateral and superior pedicle borders. Multiple morphometric studies of lumbosacral pedicles have helped define these anatomical relationships. A 2-mm "safe zone" in the lumbar spine represents the epidural space, which can be reasonably extended to $4 \mathrm{~mm}$ for lateral pedicle wall breaches given the larger mean distance between the lateral pedicle wall and the lateral exiting nerve root. ${ }^{7,55-57}$ Of the 18 pedicle breaches in this study, 16 were lateral. The remaining 2 breaches were inferior. Both occurred in the same patient and both were within the safe zone (grade 1 or $<2 \mathrm{~mm}$ ). Intraoperative $\mathrm{O}$-arm imaging identified these and corrected them at the time of surgery; the patient did not suffer any immediate postoperative or delayed morbidity. Of the lateral breaches, 11 were $<2 \mathrm{~mm}, 5$ were between 2 and $4 \mathrm{~mm}$, and none were outside the 4-mm lateral safe zone. Planned lateral breaches in 2 of the 4 L2 screws, frequently smaller diameter pedicles, were likely due to the senior surgeon's preference to maximize screw diameter at the expense of small lateral breaches, similar to the "in-out-in" approach for placement of screws in the thoracic spine. Moreover, the senior author believes that the lateral breaches at the rostral end of constructs can help avoid frank violation of the adjacent facet joint or mechanical impingement of the joint by the screwhead in extension. Future cadaveric studies are needed, however, to provide 
objective data regarding added stability by intentional Gertzbein 1 lateral breaches in the upper end of fusion constructs. Given that our experience with this technique continues to evolve, we believe the accuracy of screw placement and reproducibility in surgeons less experienced with navigation will improve. Our routine use of the Powerease (Medtronic) to cannulate the pedicles with the awl-tipped tap allows the initial passage into the pedicle with the least amount of downward pressure and minimal displacement of the spine, relative to the reference frame, and therefore higher accuracy level.

This study has multiple limitations. Data were collected prospectively from a single institution including only one attending surgeon's experience using this technique. The primary surgeon specializes in MIS; therefore, our results might not be representative of a broader group. Factors mitigating this limitation are as follows: half of the screws in this series were placed by residents learning the technique, and the patients included in this dataset represent the first 42 patients to undergo this technique, with presumed improvement in technique with time and experience. A comparison with both open and K-wire-based MIS techniques was not made because this technique has largely replaced the aforementioned ones in our practice. Whereas our experience is consistent with other reports indicating faster screw placement and overall surgery times with both spinal navigation and $\mathrm{K}$-wireless technique, screw placement time and overall operative time data were not collected as part of our dataset. Finally, we did not collect data regarding radiation exposure of the patients by CT-guided navigation. The median number of O-arm spins was 2 (range, 1 to 3 ) per case and radiation exposure of the patient varied depending on patient size and corresponding $\mathrm{O}$-arm radiation setting (ie, low versus standard versus high dose). Future studies involving CTguided navigation will focus on the extent of radiation exposure compared with traditional fluoroscopy because this remains an important health hazard for patients and surgeons in navigated spinal instrumentation.

\section{CONCLUSIONS}

Percutaneous pedicle screw placement techniques have previously relied on the use of fluoroscopy for targeting the pedicle and subsequent tapping and screw placement. We describe our method of wireless screw placement using O-arm intraopera- tive imaging and StealthStation navigation. Our review of 182 pedicle screws placed in the first 42 patients at our institution undergoing this technique reveals a safe, accurate, and reproducible method with a total breach rate of $9.9 \%$, a clinically significant breach rate of $0 \%$, and no complications. Proposed benefits of this technique include elimination of the risks and technical difficulties of $\mathrm{K}$-wires and improved accuracy provided by stereotactic navigation.

\section{ACKNOWLEDGMENTS}

A special thanks to Mike de la Flor, CMI, for the professional surgical illustrations used in this manuscript. Institutional review board approval was obtained from the Methodist Research Institute.

\section{REFERENCES}

1. Deutsch H, Boco T, Lobel J. Minimally invasive transpedicular vertebrectomy for metastatic disease to the thoracic spine. J Spinal Disord Tech. 2008;21(2):101-105.

2. Fessler RG. Minimally invasive resection of intraduralextramedullary spinal neoplasms. Neurosurgery. 2006;59(suppl 1): 1181

3. Foley KT, Holly LT, Schwender JD. Minimally invasive lumbar fusion. Spine (Phila Pa 1976). 2003;28(suppl 15):S26S35.

4. Holly LT, Schwender JD, Rouben DP, Foley KT. Minimally invasive transforaminal lumbar interbody fusion: indications, technique, and complications. Neurosurg Focus. 2006;20(3):E6.

5. Kaiser MG, Eck JC, Groff MW, et al. Guideline update for the performance of fusion procedures for degenerative disease of the lumbar spine. Part 1: introduction and methodology. J Neurosurg Spine. 2014;21(1):2-6.

6. Kostuik J, Errico T, Gleason T, Errico C. Spinal stabilization of vertebral column tumors. Spine (Phila $\mathrm{Pa}$ 1976). 1988;13(3):250-256.

7. Park DK, Thomas AO, St Clair S, Bawa M. Percutaneous lumbar and thoracic pedicle screws: a trauma experience. $J$ Spinal Disord Tech. 2014;27(3):154-161.

8. Park P, Foley KT. Minimally invasive transforaminal lumbar interbody fusion with reduction of spondylolisthesis: technique and outcomes after a minimum of 2 years' follow-up. Neurosurg Focus. 2008;25(2):E16.

9. Rath SA, Neff U, Schneider O, Richter HP. Neurosurgical management of thoracic and lumbar vertebral osteomyelitis and discitis in adults: a review of 43 consecutive surgically treated patients. Neurosurgery. 1996;38(5):926-933.

10. Scheufler K-M, Dohmen H, Vougioukas VI. Percutaneous transforaminal lumbar interbody fusion for the treatment of degenerative lumbar instability. Neurosurgery. 2007;60(4 suppl 2):203-212.

11. Steinmetz MP, Mekhail A, Benzel EC. Management of 
metastatic tumors of the spine: strategies and operative indications. Neurosurg Focus. 2001;11(6):e2.

12. Vaccaro AR, Lehman RA, Hurlbert RJ, et al. A new classification of thoracolumbar injuries: the importance of injury morphology, the integrity of the posterior ligamentous complex, and neurologic status. Spine (Phila Pa 1976). 2005;30(20):2325-2333.

13. Datta G, Gnanalingham KK, Peterson D, et al. Back pain and disability after lumbar laminectomy: is there a relationship to muscle retraction? Neurosurgery. 2004;54(6):1413-1420.

14. Gejo R, Matsui H, Kawaguchi Y, Ishihara H, Tsuji H. Serial changes in trunk muscle performance after posterior lumbar surgery. Spine (Phila Pa 1976). 1999;24(10):1023-1028.

15. Kawaguchi Y, Matsui H, Tsuji H. Back muscle injury after posterior lumbar spine surgery. A histologic and enzymatic analysis. Spine (Phila Pa 1976). 1996;21(8):941-944.

16. Ringel F, Stoffel M, Stüer C, Meyer B. Minimally invasive transmuscular pedicle screw fixation of the thoracic and lumbar spine. Neurosurgery. 2006;59(4 suppl 2):ONS361ONS366.

17. Schwender JD, Holly LT, Rouben DP, Foley KT. Minimally invasive transforaminal lumbar interbody fusion (TLIF): technical feasibility and initial results. J Spinal Disord Tech. 2005;18(suppl):S1-S6.

18. Magerl FP. Stabilization of the lower thoracic and lumbar spine with external skeletal fixation. Clin Orthop Relat Res. 1984;189:125-141.

19. Heini P, Schöll E, Wyler D, Eggli S. Fatal cardiac tamponade associated with posterior spinal instrumentation. a case report. Spine (Phila Pa 1976). 1998;23(20):2226-2230.

20. Mobbs RJ, Raley DA. Complications with K-wire insertion for percutaneous pedicle screws. $J$ Spinal Disord Tech. 2014;27(7):390-394.

21. Spitz SM, Sandhu FA, Voyadzis J-M. Percutaneous "Kwireless" pedicle screw fixation technique: an evaluation of the initial experience of 100 screws with assessment of accuracy, radiation exposure, and procedure time. J Neurosurg Spine. 2015;22(4):1-10.

22. Boucher HH. A method of spinal fusion. J Bone Joint Surg Br. 1959;41-B(2):248-259.

23. Roy-Camille R, Saillant G, Mazel C. Internal fixation of the lumbar spine with pedicle screw plating. Clin Orthop Relat Res. 1986;203:7-17

24. Fessler RG, O’Toole JE, Eichholz KM, Perez-Cruet MJ. The development of minimally invasive spine surgery. Neurosurg Clin N Am. 2006;17(4):401-409.

25. Anderson DG, Samartzis D, Shen FH, Tannoury C. Percutaneous instrumentation of the thoracic and lumbar spine. Orthop Clin North Am. 2007;38(3):401-408.

26. Choi WW, Green BA, Levi ADO. Computer-assisted fluoroscopic targeting system for pedicle screw insertion. Neurosurgery. 2000;47(4):872-878.

27. Foley KT, Gupta SK. Percutaneous pedicle screw fixation of the lumbar spine: preliminary clinical results. $J$ Neurosurg. 2002;97(suppl 1):7-12.

28. Isaacs RE, Podichetty VK, Santiago P, et al. Minimally invasive microendoscopy-assisted transforaminal lumbar interbody fusion with instrumentation. $J$ Neurosurg Spine. 2005;3(2):98-105.

29. Powers CJ, Podichetty VK, Isaacs RE. Placement of percutaneous pedicle screws without imaging guidance. Neurosurg Focus. 2006;20(3):E3.

30. Voyadzis JM. The learning curve in minimally invasive spine surgery. Semin Spine Surg. 2011;23:9-13

31. Wiesner L, Kothe R, Rüther W. Anatomic evaluation of two different techniques for the percutaneous insertion of pedicle screws in the lumbar spine. Spine (Phila Pa 1976). 1999;24(15):1599-1603.

32. Park Y, Ha JW. Comparison of one-level posterior lumbar interbody fusion performed with a minimally invasive approach or a traditional open approach. Spine (Phila $\mathrm{Pa}$ 1976). 2007;32(5):537-543.

33. Kalfas IH, Kormos DW, Murphy MA, et al. Application of frameless stereotaxy to pedicle screw fixation of the spine. $J$ Neurosurg. 1995;83(4):641-647.

34. Murphy MA, McKenzie RL, Kormos DW, Kalfas IH. Frameless stereotaxis for the insertion of lumbar pedicle screws. $J$ Clin Neurosci. 1994;1(4):257-260.

35. Kosmopoulos V, Schizas C. Pedicle screw placement accuracy: a meta-analysis. Spine (Phila Pa 1976). 2007;32(3):E111-E1120.

36. Rampersaud YR, Foley KT, Shen AC, Williams S, Solomito M. Radiation exposure to the spine surgeon during fluoroscopically assisted pedicle screw insertion. Spine (Phila Pa 1976). 2000;25(10):2637-2645.

37. Resnick DK. Prospective comparison of virtual fluoroscopy to fluoroscopy and plain radiographs for placement of lumbar pedicle screws. J Spinal Disord Tech. 2003;16(3):254260.

38. Sasso RC, Garrido BJ. Computer-assisted spinal navigation versus serial radiography and operative time for posterior spinal fusion at L5-S1. J Spinal Disord Tech. 2007;20(2):118-122.

39. Steinmann JC, Herkowitz HN, el-Kommos H, Wesolowski DP. Spinal pedicle fixation. Confirmation of an imagebased technique for screw placement. Spine (Phila Pa 1976). 1993;18(13):1856-1861.

40. Luther N, Iorgulescu JB, Geannette C, et al. Comparison of navigated versus non-navigated pedicle screw placement in 260 patients and 1434 screws: screw accuracy, screw size, and the complexity of surgery. J Spinal Disord Tech. 2015;28(5):E298-E303.

41. Rajasekaran S, Vidyadhara S, Ramesh P, Shetty AP. Randomized clinical study to compare the accuracy of navigated and non-navigated thoracic pedicle screws in deformity correction surgeries. Spine (Phila Pa 1976). 2007;32(2):E56-E64.

42. Silbermann J, Riese F, Allam Y, Reichert T, Koeppert $\mathrm{H}$, Gutberlet M. Computer tomography assessment of pedicle screw placement in lumbar and sacral spine: comparison between free-hand and $\mathrm{O}$-arm based navigation techniques. Eur Spine J. 2011;20(6):875-881.

43. Tian NF, Xu HZ. Image-guided pedicle screw insertion accuracy: a meta-analysis. Int Orthop. 2009;33(4):895-903.

44. Waschke A, Walter J, Duenisch P, Reichart R, Kalff R, Ewald C. CT-navigation versus fluoroscopy-guided placement of pedicle screws at the thoracolumbar spine: single center experience of 4, 500 screws. Eur Spine J. 2013;22(3):654-660.

45. Aoude AA, Fortin M, Figueiredo R, Jarzem P, Ouellet J, Weber MH. Methods to determine pedicle screw placement 
accuracy in spine surgery: a systematic review. Eur Spine J. 2015;24(5):990-1004.

46. Chung T, Thien C, Wang YY. A rare cause of postoperative paraplegia in minimally invasive spine surgery. Spine (Phila Pa 1976). 2014;39(3):E228-E230.

47. Scheer JK, Harvey MJ, Dahdaleh NS, Smith ZA, Fessler RG. K-wire fracture during minimally invasive transforaminal lumbar interbody fusion: report of six cases and recommendations for avoidance and management. Surg Neurol Int. 2014;5(suppl 15):S520-S522.

48. Lau D, Khan A, Terman SW, Yee T, La Marca F, Park P. Comparison of perioperative outcomes following open versus minimally invasive transforaminal lumbar interbody fusion in obese patients. Neurosurg Focus. 2013;35(2):E10.

49. Jeanneret B, Jovanovic M, Magerl F. Percutaneous diagnostic stabilization for low back pain. Correlation with results after fusion operations. Clin Orthop Relat Res. 1994;304:130-138

50. Lowery GL, Kulkarni SS. Posterior percutaneous spine instrumentation. Eur Spine J. 2000;9(suppl 1):S126-S130.

51. Schizas C, Michel J, Kosmopoulos V, Theumann N. Computer tomography assessment of pedicle screw insertion in percutaneous posterior transpedicular stabilization. Eur Spine J. 2007;16(5):613-617.

52. Smith ZA, Sugimoto K, Lawton CD, Fessler RG. Incidence of lumbar spine pedicle breach after percutaneous screw fixation: a radiographic evaluation of 601 screws in 151 patients. J Spinal Disord Tech. 2014;27(7):358-363

53. Wang MY, Pineiro G, Mummaneni PV. Stimulusevoked electromyography testing of percutaneous pedicle screws for the detection of pedicle breaches: a clinical study of 409 screws in 93 patients. J Neurosurg Spine. 2010;13(5):600605 .
54. Wiesner L, Kothe R, Schulitz KP, Rüther W. Clinical evaluation and computed tomography scan analysis of screw tracts after percutaneous insertion of pedicle screws in the lumbar spine. Spine (Phila Pa 1976). 2000;25(5):615-621.

55. Gertzbein SD, Robbins SE. Accuracy of pedicular screw placement in vivo. Spine (Phila Pa 1976). 1989;15(1):11-14.

56. Lien SB, Liou NH, Wu SS. Analysis of anatomic morphometry of the pedicles and the safe zone for throughpedicle procedures in the thoracic and lumbar spine. Eur Spine J. 2007;16(8):1215-1222.

57. Parker SL, McGirt MJ, Farber SH, et al. Accuracy of free-hand pedicle screws in the thoracic and lumbar spine: analysis of 6816 consecutive screws. Neurosurgery. 2011;68(1):170-178.

Disclosures and COI: The authors received no funding for this study and report no conflicts of interest. Sadrameli and Jafrani are co-first authors.

Corresponding Author: Saeed S. Sadrameli, MD, 6505 Fannin St, Suite 901, Houston, TX 77030. Phone: (281) 743-1385; Email: ssadrameli@ houstonmethodist.org.

Published 21 December 2018

This manuscript is generously published free of charge by ISASS, the International Society for the Advancement of Spine Surgery. Copyright (c) 2018 ISASS. To see more or order reprints or permissions, see http://ijssurgery.com. 